\title{
Transforming Territories: A Landscape of "In-Tension-Alities"
}

\author{
GIOVANNI SANTAMARIA \\ New York Institute of Technology
}

\begin{abstract}
"Territory is our condition of existence, the positive product of the collaboration between man and nature, and also our irreplaceable patrimony. In the territory is the inner meaning of man and civilization, their relationship with the natural world..." (Muratori, S., Civilta' e Territorio, 1967)
\end{abstract}

\section{THE BACKSTAGE: GLOBAL GEOGRAPHIES AS RESULT OF SYSTEMS OF ACTIONS/REACTIONS.}

The flow of people, resources, material and immaterial goods, and at the same time regimes and strategies of control, have always shaped/reshaped our geographies and processes of urbanization. Therefore built and unbuilt landscapes have been characterized by gradual or dramatic changes, leading to new architectural typologies and urban morphologies corresponding to the transformation of means of production, distribution, circulation, consumption and to the shift of political, economic and ideological realms. The effects of these processes on structure and quality of space and life could be described as part of a complex Urban Metabolism ${ }^{1}$ which looks at the city and its territory as a complex organism. This dynamic landscape has reached a high level of complexity where natural environments (geology, hydrology, topography) and cultural environments (productive lands, urban settlements, infrastructural networks) need to be synergistically understood as part of an articulated ecological system, with both micro and macro implications. It is the synthesis of geographic-historical contents (collective values), aesthetic-perceptual contents (individual values), and ecological-natural contents (biological values) ${ }^{2}$, influenced more and more by natural and man-made disasters caused by climate change and human conflicts. Since the city as a definable entity and product of predetermined models has become obsolete, we are now called to work with a collage of fragments, heterogeneous and dynamic, often in opposition and unpredictable, subjected to the balance of variable forces, with their own order and rules, and their own ways of evolving, which we have to understand and manage ${ }^{3}$. This determines the need for new tools and methods to observe, record and assess urban phenomena, and the data regarding them, towards more sensitive interventions.

\section{THE STAGE: SHIFTING THEORETICAL APPROACHES AND DECODING PARADIGMS.}

This global perspective allows us to shift our focus from a utopia of canonic forms to heterotopic processes and performable methodologies, to modify our way of understanding and approaching urban contexts, to overcome the emphasis towards towns and cities, buildings and forms, and to understand anew the processes of shrinkage and growth of these subjects within their landscapes. Therefore we need to rethink these in a systematic way, according to the ecological, infrastructural, technical, social, and political challenges that they present and derive from, and their impacts on metropolitan areas.

For these reasons design interventions must proactively operate across greater extents of time and dimensional scales, from the geography of entire regions, to the engineering and new techniques concerning building and environmental components, capable of dealing with critical problems such as water, waste and energy management, reuse, recycling and reclaiming of building and land, consumption of resources, pollution and environmental risks. At the same time, these interventions have to deeply understand the collective memory of the landscapes in which they operate and the DNA of the anthropological processes, to be capable of responsibly and coherently redirect them towards a more sustainable future.

This approach focuses on the several levels of interactions within open fields as coordinated ecosystems, rather then on specific architectural objects and spaces. It requires reimagining tools, expertise, roles, and responsibilities that today are often rigidly separated by hyper-bureaucratic structures which do not consider the cross-relationships between those divided scales and fields.

What is required is a multidimensional and multidisciplinary approach, capable of crossing simultaneously: Scales -from the global one of networked political, economic logistics and natural strategies, to the local ones of micro-oriented interventions related to the needs of specific communities and to the local natural life cycles; Fields -from the strictly urban and infrastructural ones, and the different gradients of human manipulation of productive lands, to the natural ones related to flora and fauna, soil, water, and air, and to the ephemeral dimensions of data and information; Time/Space-from the status quo and the understanding of the past as complex process of actions and reactions, to the future, as projection on a global scale of issues concerning the shrinkage and rapid growth of metropolitan areas, with their uncontrolled consumption of space. The corridors of technological, financial and productive dominance over settlements, determine the physical and social exclusion and isolation that generate conflict and inequalities. In fact, while unifying and overcoming 


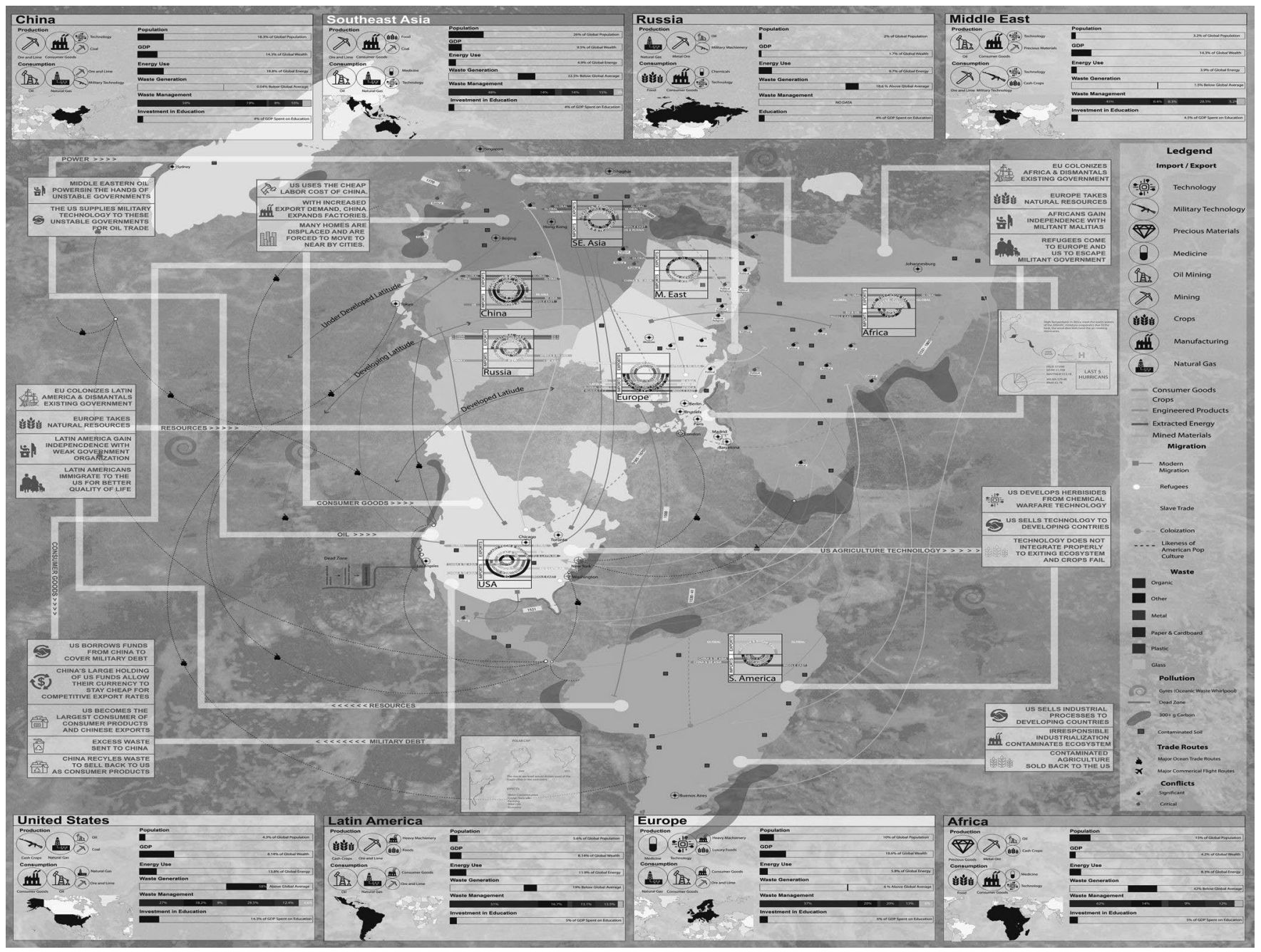

Figure 1: Material and immaterial global flows and territorial dynamics. (SoAD at NYIT_ Thesis 2018 - map by Vuono, V., Hinali, S., Hurtado, J.)

differences related to geographical and political boundaries at a large scale, top-down infrastructure can often act then as a divider of local territories and sponsor social disengagement, stemming from the dissonance between abstract and physical experiences of urban and ecological patterns. This panorama has generated a sort of postindustrial MetaUrbanism, as programmatic layering: textures and flows where new design experiments introduce the territorial scale within the consolidated city, into the blurred zones between suburbs, into the terrain vague, into productive areas, into ecologically sensitive sites and metropolitan deserts.

These interstitial zones of friction and exchange produce the complex ecology of our current landscapes, which overcoming the deterministic paradigm, open to diversity and indetermination. The understanding of organizational and working processes of ecology may help to generate more adaptable and resilient urban structures, operating with designed redundancies to avoid the collapse of essential systems. It is crucial to understand topography and its performative qualities as creative realm for design proposals, through which it remains possible to find a proactive common ground between Architecture, Landscape and Urban Design, with their individual peculiarities and similarities.

The first Land Art experiments provided an example of this in terms of scalar, formal and spatial expressions, while more recent proposals introduced temporal processes and ecological systems as primary foci, underlining a project's life cycle within its context. If we consider our landscapes as the pluralistic and active expression of our societies, of the ideological and metaphysical values shaping these, then landscape becomes the "active cultural agent" ${ }^{4}$ defined by J. Corner, that proactively and critically synthesize our way of being and adapting to the context we operate in and express through, continuously reactivating and rethinking it, towards the production of new meanings. Within this landscape we could find the final and perhaps purest concept of democracy, since everyone is equally but differently called to take care of it, to equally and individually belong to it, and critically 
operate in it within a community. Being a synthesis of man made and natural structures and functions -not only in image- our landscapes become a fundamental way to decode contemporary metropolitan regions and to understand their values and performability. We perceive these landscapes and at the same time, as we act, we redefine them, which occurrs even when describing them. We then become part of the story, as witnesses and actors recalling and generating new memories, without which a future "prophecy," or any "hope," would be impossible, as stated by C. Rowe ${ }^{5}$. This evolving process deals with and creates values of differentiation and persistence, or memory, which are relevant as an environment changes and survives, critically redefining the Urban Ecologies ${ }^{6}$ we live in and move thorough, as they are characterized by heterogeneity and complexity of interactions, often between residual or neglected areas ripe with potentials. These new urban systems may be open and strategically integrated into the landscape, defining processes of change that involve an overall regional metabolism.

Within this metabolic approach, and considering both built and unbuilt environments, we operate and organize the change by means of Maintenance, Transformation, and Substitution. These are different but coordinated degrees of regeneration. While Maintenance is a way of preserving and improving the status quo, especially in historically consolidated urban, productive, and natural contexts, often with symbolic values and indicators of the identity of the place; Transformation involves structural changes to the system and its functioning or program, operating on crucial parts of it; and then Substitution is an action that implies the total rethinking of structure and form of a specific system or its part, replacing the old with a radically new one, thus changing the qualities of its context as well.

This Metabolic Intervention concerns several dimensional scales, space and time frames as well, from the specific, related to the object and its components, to the regional and territorial ones beyond political and administrative boundaries, to the global ones regarding synergic flows and dynamics. It requires thinking of new coordinated and creative strategies, tools and codes to plan, design and manage the scales of the landscape, to envision and invest in future development. Therefore it is crucial to consider the entire and networked life cycle of the system environment, its formation, growth, consumption and its eventual destruction and reuse. It is similar to the physical metabolism of individuals, which manages the biological, chemical, and energetic transformations within a human body and its livelihood. This enables professional operators in the fields of architecture and planning to re-think their roles, tasks and objectives when designing buildings, cities and landscapes, to be considered as adaptable and flexible processes, as integrated and interactive parts of a more complex territorial and environmental entity, still searching for new physical and spatial possibilities of expression to define a place, and in applying new knowledge to reveal new strategies of management and decision making.At the territorial scale, we have to envision a new paradigm of a networked city, formed by differentiated but connected epicenters that identify strategic locations for new design interventions as densifying nodes, dynamic and open to shifting functions. It is a sort of capillary system that gradually evolves, balancing the effects of the change of its parts in response to the all, to localize and direct modalities and dimensions of the transformation in critically selective ways. This specialized, hierarchical and flexible polycentric network of existing and new integrated nodes, makes the overall system sustainable and adaptable, always proactively facilitating new alternative paths and synapses, avoiding the collapse of a structure because of changing contextual conditions. In this context, a crisis becomes an opportunity for the development of new strategies, redefining connectivity based on a sustainable balance of growth and available resources, in a competitive framework.

The new cores that characterize a project at the scale of the landscape, unlike the previous centralized paradigms operating at the scale of the consolidated city, constitute a sort of episodic but integrated model which creates new territorial and urban structures. Here the old nodes can gain new symbolic meaning, as 'mediators' actively integrated with the new elements and capable of orienting the existing communities to the new networked environment, rendering it recognizable and attractive, accordingly to Donadieu ${ }^{7}$. This system of heterogeneous epicenters within and throughout the landscape is territorially linked and locally specialized accordingly to other close nodes and to the networked environment in which they operate.

At the microscale these epicenters, as points of accumulation of territorial forces, work like permeable clusters of localized exchanges, and are open to opportunities for Landscape Architecture. This finds place in the problematic of 'in between spaces,' where elements of different natures collide: where infrastructures cross city, landscape, and productive lands; where the city meets and merges with its surroundings. These thresholds in which informal, spontaneous, uncontrolled change find place, open for creative strategies for growth, as clarified by Charles Waldheim ${ }^{8}$.

Through these performative design interventions, we can give form to a rhizomatous and diverse process of transformation of our urban landscapes which we aim to make resilient, so to be capable of absorbing, more than resisting, the changes of dynamic environmental conditions, and of retaining most of their structure and functions once these return to the original state. This is represented through proactive strategies and design experimentations geared towards futuristic visions framed within a landscape urbanism approach, since 


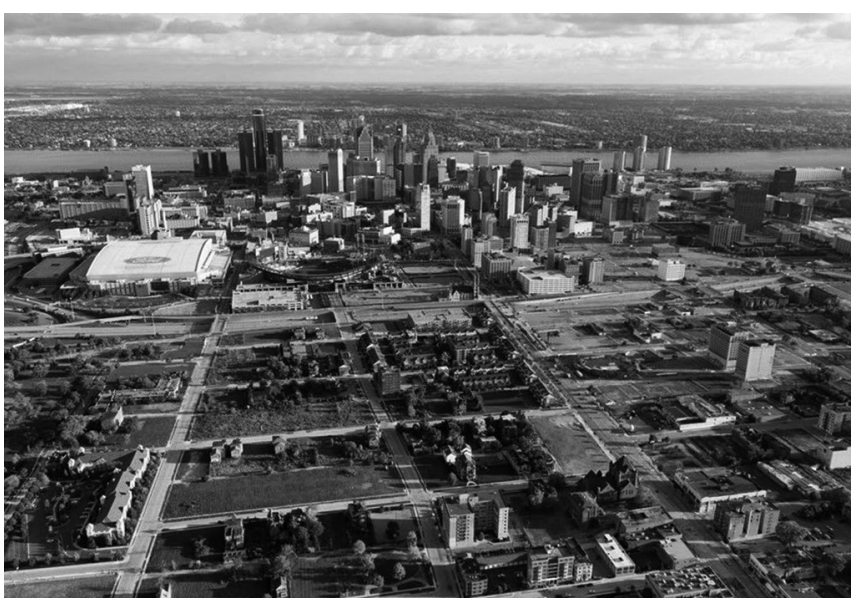

Figure 2: Aerial view of the downtown of Detroit- the spacial effects of the shrinking process of the city.

If we cannot control the volatile tides of change, we can learn to build better boats. We can design and redesign organization, institutions, and systems to better absorb disruption, operate under a wider variety of conditions, and shift more fluidly between several circumstances. To do that we need to understand the concept of resilience as continuous and rhizomatous process of transformation/adaptation. ${ }^{9}$

\section{THE ACTION: CONVERTING CRITICALITIES TO OPPORTUNITIES FOR PROACTIVE STRATEGIES.}

This background describes the complexity within which operate some of the current design strategies noted below. They underline the great potential of our postindustrial environments. These express different approaches to the design of urban transformations, often driven and promoted by local communities, rather than a centralized institution. They are also focused on strategies- more than models- operating systemically at multiple levels, not only on formal/aesthetic ones, but involving issues such as pollution, ecological risks, social imbalance, sustainable production, and recognition of values of the 'ordinary heritage.'

This is the case of Detroit for example, which among several other American cities, has been deeply affected by the crisis in the decline of automobile production. The shrinking process has involved mostly the downtown of the city, its closer surrounding and the infrastructural system, meanwhile several gated communities have been growing within the metropolitan area. This depopulated no-mans land and incredibly suggestive 'urban deserts', replaced the traditional American sprawl of single family houses just outside the downtown area. It has led to a new fragmented landscape suggesting renewed modalities of using and sharing it by the remaining population, introducing an unprecedented re-combination of the residential lots and blocks and their strategies of management. Plenty of literature and studies have been produced

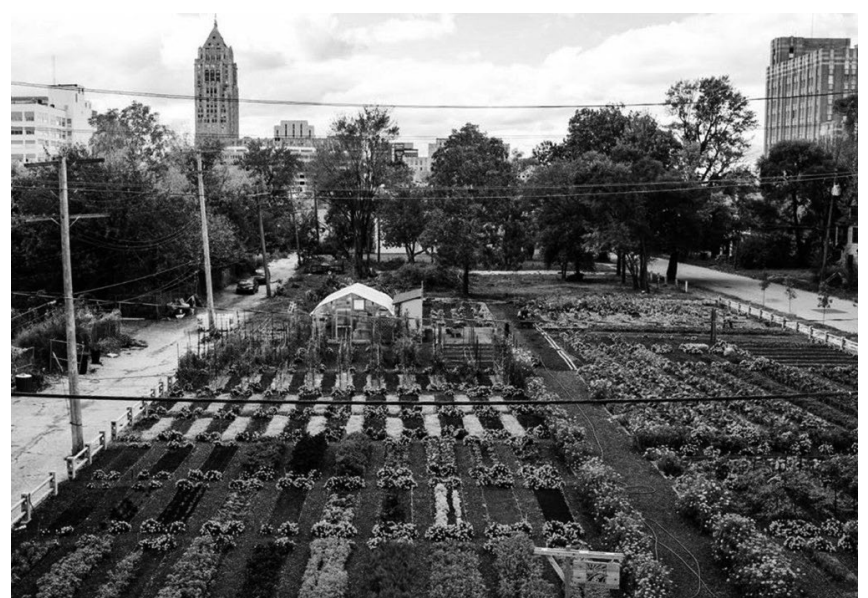

Figure 3: Processes of bottom-up transformation in Detroit- urban farming and shared ownership of the vacant lots.

about this postindustrial urban phenomenon and its several dramatic effects on the physical and social environment. In the last 15-20 years this has also given to the city the opportunity to re-think itself, opening to experimental strategies of adaptation, and redirecting these transformations in creative and proactive ways. Several art and recently agriculturallybased initiatives have been introduced to repopulate the cityscape, its structure and also its social setting. Informal and less institutionalized projects are reactivating bottom-up selected areas of the city, attracting new dynamics and proactively sustainable local strategies that are readapting the public realm. Not far away from well-known cultural institutions such as the DIA museum with its Matisse, Degas and the murals by Rivera which paradoxically celebrate, or perhaps wisely criticize, the mechanistic society of production, the MOCAD and the Red Bull House of Art today represent the new face of the art scene in Detroit, which elected the city itself as core for new experimental interventions.

In the same way and since 1986, the Heidelberg Art Project by the artist Tyree Guyton in the McDougall-Hunt Neighborhood, has been creatively and progressively transforming the empty houses and lots of the area as a colorful and eclectic open air museum, a land art piece that celebrates crisis and decay of the city, and at the same time of the ideology that created that urban- social- economic model. In the Eastern Market district, the Adopt a Lot program has introduced new strategies of productive adaptation. Here several empty lots, were transformed for community self-managed and free urban farming. Similarly in the North End Neighborhood, the AgriHood project by Tyson Geresh introduces new possibilities for a more sensitive and adaptable urban planning. Two acres of urban farming are located here as part of the nonprofit Michigan Farming Initiative (MUFI) where 50,000 pounds of fresh vegetables have been produced per year, mostly by and for the surrounding low-income community. This project is unique, having at the center of a residential planning 


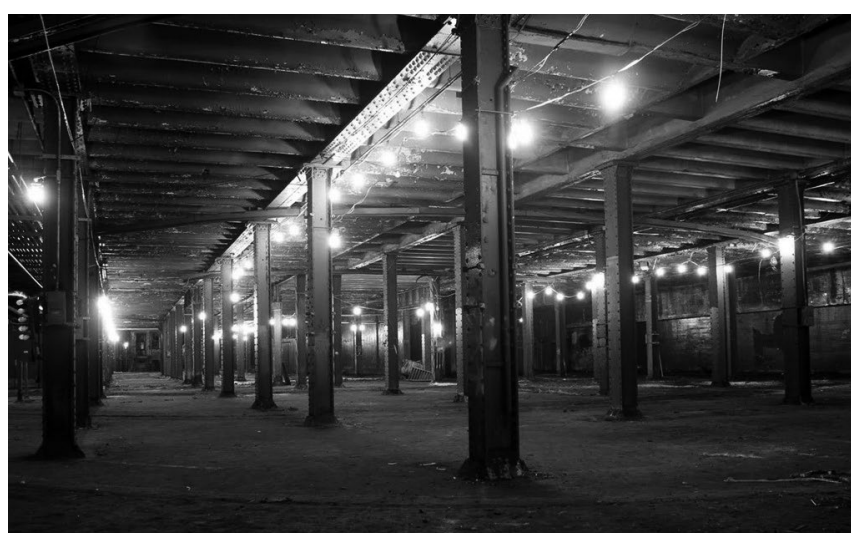

Figure 4: Williamsburg Bridge Trolley Terminal in the Lower East Side of Manhattan-New York, active until 1948.

proposal, a working farm as social and spatial incubator to operate also at political and administrative levels, directing the future process of transformation/gentrification on a more sustainable path, and to use low-cost building systems like shipping containers and recycled construction materials from the former local industrial.

In New York, where the process of de-industrialization has been apparently slower and less dramatic because of the more heterogeneous production systems and due to the presence of a stronger and a more diverse metropolitan economy, the transformation that has involved all the urban waterfronts, has been the key in changing dynamics and morphology of the city, often through an aggressive gentrification, barely balanced by its 'green' components. Piers, highways and factories along the water have been in fact demolished, replaced, transformed, densified and embellished during the last 40-50 years, starting from the island of Manhattan (Battery Park and Hudson River Park), to Queens (Long Island City), Brooklyn (Dumbo and Brooklyn Bridge Park), Staten Island (Fresh Kills Park) and Governors Island (The Hills project), with progressively more attention to the design of spaces for leisure and public services, and in the more recent projects, also to ecological and environmental priorities such as rising currents, pollution and waste, more than focusing on pure real estate speculations, which nevertheless, remain the main economic engine of these transformation processes.

Along with the shoreline development, more recent projects in the city have been operating with some of the disused fragments of infrastructure within core neighborhoods, as is the case of the well-known 1.45 miles-long project of the High Line by Field Operation with Diller Scofidio + Renfro through the Meatpacking District and Chelsea on the West side of Manhattan. This elevated green promenade has been opening in phases from 2006 until 2017, experimenting a new approach in the US towards the reuse of infrastructural archeology, metabolically reintroduced into the public realm

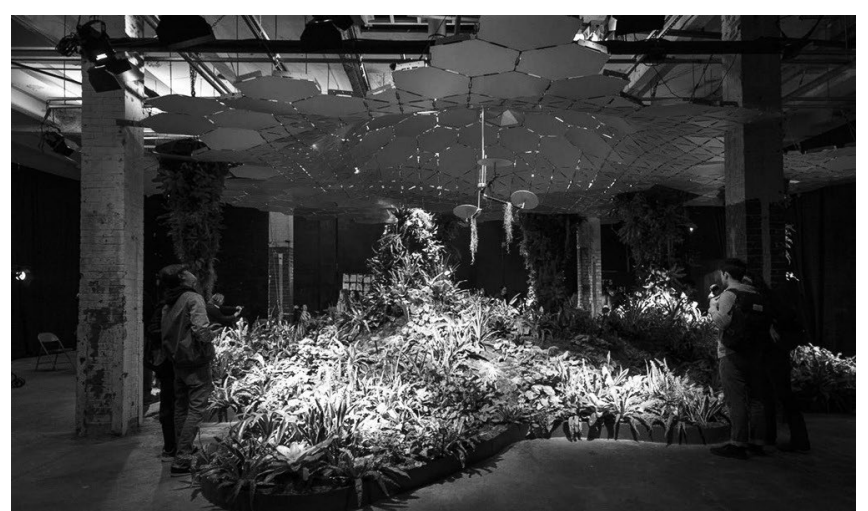

Figure 5: "Lowline" or "Delancey Undergroud." Underground Park cofounded by Ramsey, J. and Barasch, D. with ARUP- temporary installation, 2015-17.

of the city. At the same time this has boosted a strong process of gentrification of the entire area through mostly small acupunctural interventions, except for the last of these at its norther terminus. In fact, here are located the 28 acres of the Hudson Yards Project by Kohn Pedersen Fox Associates, on the former site of the West Side Rail Yard, and which is dramatically changing the skyline of the city and the balance of its dynamics. Several are the local activities and residents that have been leaving these areas due to the effects of the gentrification that transformed the previous manufacturing district, into a product for the global tourist who now enjoys the roof scape of the city. Far from the 'inconveniences' of the street level, it has created a sort of 'elegant living room' for rich investors (often international) who can afford the bird'seye view of the Hudson River sunset, beyond the gated and controlled 'front yard' represented by the High Line Park.

On the opposite side of the island, and of the surface of the ground, are the three blocks from Essex to Clinton Street on the Lower East Side, of the former Williamsburg Bridge Trolley Terminal adjacent to the Essex Street subway station active until 1948. The so-called "Lowline" or Delancey Underground, now legally part of the $1,650,000$ sq. ft. Seward Park Urban Renewal Area, is open to new creative possibilities to rethink and reuse the extended underground network of spaces in the city. This first underground park, co-founded by James Ramsey and Dan Barasch with the Arup group, opened in 2015 thanks to a Kickstarter campaign by executive producer Robyn Shapiro and industrial designer Ed Jacobs. This allowed the installation called Imagining the Lowline, of a 30 feet solar canopy capable of directing sunlight into unlit spaces through a "remote skylight" designed by RAAD studio. This optical system is made of parabolic reflectors- a sun collector dish and a sun distribution dish- connected by an "heliotube" containing optical fiber cables that channel the light into a live cultivated underground area, creating a park that brings new possibilities of life and programs in these forgotten infrastructural spaces. The great resonance of the project within the community, and the strong support offered by politicians, 
public administration and media, led to an extension of the closing date of the installation to March 2017. This introduced a sort of reverse code in approaching the spaces of the city redefining their values, which become more experiential than commercial, more collective than individual, more integrative and performative than isolative and constative.

Through these new typologies of synergic and contextuallyaware projects, we are called to manage, adapt and reorganize the active and flexible sets of spatial systems within our environments, to critically identify sensitive locations for remapping original design vocabularies, strategies and methodologies to generate renewed 'po(i)etic'10 effects at a greater scale, transforming challenges into opportunities.

\section{ENDNOTES}

1. Urban Metabolism is mostly related to the scale of an Urban Region which supports its own sustainable growth in terms of spatial, social, energetic, and economic balance through internal and external exchange processes improving systems of production and reproduction and its power of attraction. A. Wolman in his book entitled A typical American City (1965) defines urban metabolism as 'all commodities needed to sustain a city's inhabitants at home, at work, and at play,' but his approach was mostly focused on the physical aspects of the balance of production and exchange of energy and natural resources, more than on their concept is included in C. Kennedy's book Changing Metabolism of Cities (2007) concept is included in C. Kennedy's book Changing Metabolism of Cities (2007) where he defined it as a totality of the technical and socio economic processes
that occur in cities, resulting in growth, production of energy, and elimination of that occur in cities, resulting in growth, production of energy, and elimination of cycle of an urban environment works and has interesting references to P. Geddes' cycle of an urban environment works and has interesting references to P. Geddes' related social effects.

2. This concept is explored philosophically by Assunto, R. 1973. II Paesaggio e I'Estetica. Napoli, Guerini.

3. References to this concept by Neuteling, W.J., are described in GUST (AA.VV.) 1999. The Urban Condition: Space, Community, and Self in the Contemporary Metropolis. Rotterdam, 010 Publisher, pp.36-39.

4. Corner, J. \& Bick H., A. 2014. The Landscape Imagination. New York, Princeton Architectural Press, p.111

5. Rowe, C. \& Koetter F. 1978. Collage City. Cambridge Mass, MIT Press, p. 124

6. This concept has been explored and consolidate in a book titled Ecological Urbanism by Mostafavi, M. \& Doherty, G. 2010. Boston, Harvard University.

7. Donadieu, P. 2002. La societe' Paysagiste. Arles, Actes Sud, p. 86

8. Waldheim, C. 2006. The Landscape Urbanism Reader. New York, Princeton Architectural Press, pp. 64-67

9. Zolli, A. \& Healy, A.M. 2012. Resilience. Why things bounce back. London, Headline Publishing Group, p. 28

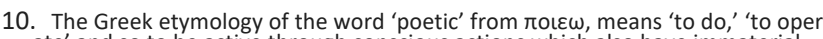
ate' and so to be active through conscious actions which also have immaterial values or effects, and are esthetically balanced. This is also related to the way $M$. Heidegger used the same word 'poetic' as the only way through which humans can inhabit a space, actively transforming it into a 'specific' place. 